\section{2 \\ DEVELOPMENT OF A TRAINING FOR THE USE OF A GUIDELINE BY OCCUPATIONAL HEALTH PROFESSIONALS}

Marloes Vooijs*, Daniël Bossen, Jan L Hoving, Haije Wind, Monique HW Frings-Dresen. Academic Medical Centre, Department: Coronel Institute of Occupational Health, Amsterdam Public Health research institute, Amsterdam, The Netherlands

\subsection{6/oemed-2018-ICOHabstracts.302}

Introduction We developed a guideline for occupational health professionals (OHPs) to optimise guidance and assessment of people with a chronic disease. Since adherence to such guidelines is generally low, a training can be used to increase OHPs compliance. Because limited evidence is available on the development of a guideline training, this study provides insight on how such a training can be developed.

Methods A qualitative approach of four steps was used. First, focus groups were held to explore OHPs training needs. OHPs prioritised guideline evidence based on implementation needs, and required knowledge and skills to use the evidence in practice. Second, based on the training needs, learning objectives were formulated by the researchers. Third, experts in the field of education were interviewed to explore relevant teaching methods. Finally, researchers integrated all results in a final training approach to optimise OHPs guidance and assessment.

Results OHPs reported various training needs, after which 17 learning objectives were formulated, such as identification of factors and effective interventions that influence work participation, and stimulating the own role of people with a chronic disease. To provide these learning goals in practice, experts reported various teaching methods, including the provision of homework, case study, role play, discussion of best practices, debate, and interview with stakeholders. The training needs and teaching methods were integrated in a six hour training day.

Discussion This study shows that OHPs indicated several training needs to use the guideline in practice. These training needs can be provided through the use of various teaching methods, which are mostly closely related to OHPs daily practice. Providing an overview of the proces of development of may support researchers and developers of occupational guidelines in the development of other guideline trainings.

\section{PROMOTION OF FARMER'S HEALTH THROUGH EXTENSION IN IRELAND}

1J McNamara*, ${ }^{2} \mathrm{P}$ Griffin, ${ }^{3} \mathrm{~N}$ Richardson. ${ }^{1}$ Teagasc- Agriculture and Food Development Authority, Kildalton, Co Kilkenny, Ireland; ${ }^{2}$ Health and Safety Authority, Dublin 1, Ireland; ${ }^{3}$ Centre for Men's Health, Institute of Technology, Carlow, Ireland

\subsection{6/oemed-2018-ICOHabstracts.303}

Introduction In Ireland, the majority of farmers are selfemployed and studies have indicated higher levels of mortality in the working age category (16-65 years old) than other occupational groups. Within the discipline of health promotion, applying a broadly based 'biopsychosocial' approach in contrast to the more narrow 'biomedical' one has been advocated to achieve health gains. In Ireland a state extension system (Teagasc) is in place to provide research-supported advice and training to farmers on farming practice and associated quality of life issues. Extension has been active in promoting health among farmers in association with health professionals especially during the last decade.
Methods A retrospective review was conducted to identify major national initiatives with extension involvement to either research or promote health among farmers in Ireland. The period from 1 st January 2006 to 31 st December 2016 was used as the review reference period.

Results The survey identified nine major health promotion initiatives involving extension in Ireland in the reference period. Three involved research on the following topics: disability causes (PhD); health and musculoskeletal disorders (PhD); farmer stress (Masters). One involved inclusion of occupational health in a statutory farm health and safety code of practice. Two involved provision of training to extension staff on health promotion as a component of the national men's health training programme (ENGAGE). One involved a series of health promotion exhibits, including blood pressure checking, at outdoor farming events. One involved the national distribution of a farmer health booklet and one involved publication of a series of extension media releases and articles on aspects of farmer's health.

Conclusion The retrospective review has identified considerable engagement by extension with health promotion among Irish farmers. This engagement involved: research, staff training, and production of a major publication and provision of advice to farmers on health using farming media.

\section{RESPIRATORY PROTECTION TRAINING FOR HEALTHCARE WORKERS}

${ }^{1}$ MG Ryan*, ${ }^{2} \mathrm{~L}$ Pompeii. ${ }^{1}$ President, American Association of Occupational Health Nurses (AAOHN), Chicago, Illinois, USA; ${ }^{2}$ Associate Professor, University of Texas School of Public Health, Houston, Texas, USA

\subsection{6/oemed-2018-ICOHabstracts.304}

Introduction This presentation will provide an overview of the development of the National Institute of Occupational Safety and Health (NIOSH) funded Respiratory Protection training courses for Health Care Workers and Occupational and Environmental Health Nurses (OHNs). Topical content and access information details will be provided.

Methods After the Institute of Medicine identified the knowledge gaps among OHNs pertaining to respiratory protection for workers, AAOHN collaborated with NIOSH, the American Board of Occupational Health Nurses, the American Nurses Association, and the Association of Occupational Health Professionals to form an advisory board of respiratory protection experts. The advisory board guided development of the respiratory protection training courses led by university researchers which aimed to increase the knowledge of Occupational Safety and Health Administration's Respiratory Protection Standard, the Centres for Disease Control and Prevention's (CDC) Airborne Precautions, and the use of the N95 respirator in healthcare.

Result Four training courses were developed that are free and offer continuing education credit at www.aaohn.org/academy:

- OHN: Respiratory Protection Education and Resources -a ten-module resource to train OHNs as a Respiratory Protection Administrator;

- Respiratory Protection for Healthcare Workers - contains two modules pertaining to frontline healthcare worker respiratory protection focusing on the CDC's airborne precautions including N95 use; 